\title{
Health benefits of milk and functional dairy products
}

\begin{abstract}
Dairy products have so far been in the front line in the development of functional foods. Fermented dairy products have traditionally been considered to have health benefits and thus broadening the product range to other types of health-promoting products is quite natural for the dairy industry. Functional dairy products have recently been increasingly available in the daily-life which has gained increasing popularity in the past few years. Consumer's interest about personal health is reasons in establishing markets for functional dairy products. In the near future we will definitely see more products targeted for special consumer groups. This mini-review provides the reader with a brief overview of the field. It consists of two parts giving state-of-truth information about the following topics: Milk and its health benefits and functional dairy products. This article should be of benefit to everyone involved with food science and nutrition, research on functional diary product, and food product development.
\end{abstract}

Keywords: milk, yogurt, health benefit, probiotics, dairy, functional products
Volume 4 Issue 4 - 2017

\author{
Mohammed Abdalbasit A Gasmalla, ${ }^{1,2}$ \\ Habtamu A Tessema, ${ }^{1,3}$ Ayah Salaheldin, ${ }^{4}$ \\ Kamal Alahmad,' Hinawi AM Hassanin,' \\ Waleed Aboshora ${ }^{1,5}$ \\ 'School of Food Science and Technology, Jiangnan University, \\ China \\ ${ }^{2}$ Department of Nutrition \& Food technology, Omdurman \\ Islamic University, Sudan \\ ${ }^{3}$ Department of Food process Engineering,Addis Ababa Science \\ and Technology University, Ethiopia \\ ${ }^{4}$ Department of Animal Science, University of Gezira, Sudan \\ ${ }^{5}$ Department of Food Processing Engineering, Al Imam Almahdi \\ University, Sudan
}

Correspondence: Mohammed Abdalbasit A Gasmalla, School of Food Science and Technology, Jiangnan University, I 800 Lihu Avenue, Wuxi 214I22, Jiangsu, China, Tel +86-15152207032, Emailmoh_8282@hotmail.com

Received: January 26, 2017 | Published: June 22, 2017

\section{Introduction}

Milk is considered as a nearly complete food since it is a good source of protein, fat and major minerals. Also, milk and milk products are main constituents of the daily diet, especially for vulnerable groups such as infant's school age children and old age. ${ }^{1,2}$ Several studies have reported the distribution and occurrence of the essential components in various animal milks ${ }^{3}$ Milk is one of the most important nutrition food sources besides breast milk for infants and babies. In fact, consumption of dairy products has recently been linked to health benefits that are the direct antitheses of diseases and complexity that related to overweight and obesity. For example, individuals that consume dairy products are more likely to have lower weight, ${ }^{4}$ lower blood pressure,, 56 and decreased risk of stroke, colon cancer $^{7-9}$ and osteoporosis. ${ }^{10,11}$ There is a wide range of functional foods that were developed recently and many of them are being produced in all over the world including probiotic, prebiotic and synbiotic foods as well as foods enriched with fat-reduced, salt-reduced foods or sugar-reduced foods, antioxidants and phytosterols as shown in Figure 1.

Among these foods, probiotic functional food has exerted positive effects on the overall health. We can divide it in both probiotic dairy foods and probiotic non-dairy foods. The market of probiotic dairy foods is increasing annually. An increased demand for dairy probiotic products comes from health promotion effects of probiotic bacteria which are originally initiated from milk products, bioactive compounds of fermented dairy products and prevention of lactose intolerance. Therefore, development of these products is a key research priority for food design and a challenge for both industry and science sectors. ${ }^{12}$ This mini-review is an attempt to show some advances that have been made connecting milk and functional diary product.

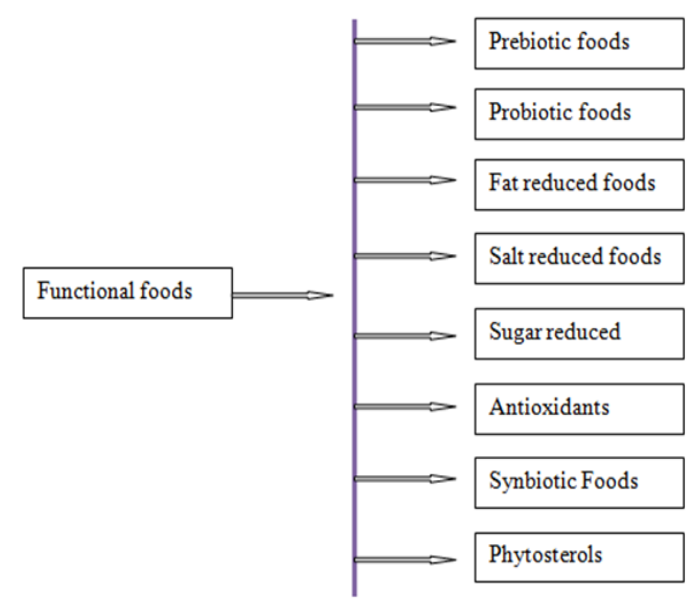

Figure I Most of the functional foods that being produced in all over the world.

\section{Milk and its health benefits}

Milk is a composite physiological fluid that facilitates postnatal adaptation of baby through digestive maturation simultaneously by providing the bioactive components and nutrients. It supports lymphoid tissues development and establishment of symbiotic micro flora. The importance, potency and the quantity of milk bioactive compounds are possibly more than old consideration..$^{12,13}$ They comprise certain specific organic acids, vitamin A, B12, D, riboflavin 
calcium, carbohydrates, phosphorous, selenium, magnesium, zinc, proteins, bioactive peptides and oligosaccharides. They mostly emerge during fermentation or digestive processes while in some cases these are components of fresh milk. The possible mechanisms for cholesterol decreasing or removal by probiotic bacteria and fermented dairy products include inhibition of intestinal cholesterol absorption. FAs having medium chain whey proteins and other minerals may add positive result of dairy products on body mass. The dairy proteins play a vital role in food intake regulation, satiety and metabolic distracts relating to obesity. Blood pressure may be affected by lactic acid bacteria, milk proteins, peptides and calcium. Milk fat contains certain components having the functional significance. Antimicrobial effects are exerted by sphingolipids and their active metabolites either directly or upon their digestion. Whey was studied as a medicine as well as an aphrodisiac and skin balm during the Middle Age. Whey proteins, i.e. $\alpha$-lactalbumin, lactoferrin, lactoperoxidase, serum albumin and $\beta$-lactoglobulin acquire important biological and nutritional properties particularly regarding disease prevention. Immunostimulatory, anticarcinogenic and antimicrobial are other whey protein activities that promote health. Milk products and their components take part in regulating the body mass through satiety signals. Therefore, whey proteins include physiological milk components for individuals with metabolic syndrome and obesity. Whey protein in high protein milk products may improve insulin sensitivity and reduce fat deposition. The bioavailability of trace elements and minerals i.e. manganese, calcium, magnesium, iron, selenium and zinc is also improved by milk proteins and peptides. ${ }^{13}$

The health benefits of milk and dairy products are known to humanity and may be attributed to the biologically active compounds that are existing in milk. Beside the modification of several milk components, proboscis may also act directly as preventive agents, or in therapy of some sever disease. The functional role of fermented dairy products is either directly through interaction with consumed microorganisms or, indirectly, as a result of action of microbial metabolites like nutrients, generated during the fermentation process. The health promoting mechanisms of probiotic action are mostly based on the positive effect they exert on the immunity response. ${ }^{14}$

Milk facilitates the maturation of digestive tube and cell growth of a baby in gastrointestinal tract (GIT). Donovan ${ }^{15}$ reported that milk is a complex combination of nutrients such as particular bioactive saccharides, lipids and proteins content which assist to regulate the development of GIT by representing the important signals. On the other hand, Morrow et al. ${ }^{16}$ \& Newburg et al. ${ }^{17}$ concluded that milk is a source of communication in case of mother and the newborn child that influences the role of mucosal immunity and minimizes the risk of infection. Milk has a wide various biologically active substances for instance, enzymes, immunoglobulins, oligosaccharides, antimicrobial peptides, hormones, cytokines, and the growth factors besides the basic saccharides, proteins and lipids as reported by Pouliot. ${ }^{18}$ Milk components are particular parts of immune system of newborn and they assist to stimulate and sustain the baby immune homeostasis. Neutrophiles, macrophages and T-lymphocytes as the heterogeneous population of milk cells play an important role in the defense against pathogenic bacteria.

So far, more than 60 different enzymes are recognized in milk and during the heat treatment the most of those enzymes will destroy and become inactive. The heat processing at high level of temperatures causes not only digestion enzymes denaturation (amylases, proteinases, phosphatases, lipases) but also digestion those enzymes having antioxidant and antimicrobial characteristics. These special characteristics are essential in milk stability as well as in the defense against pathogens; catalase, oxidoreductase, xanthine, lysozyme, dismutase, superoxide, lactoperoxidase, ribonuclease and myeloperoxidase. Milk antimicrobial agents have been shown bactericidal and even bacteriostatic behavior. They are transmitted to progeny where they protect the progeny from highly contagious disorders. Lactoperoxidase, xanthine, oxidoreductase and lysozyme are the other best protecting factors in additions to immunoglobulin. ${ }^{19,20}$ Lactoperoxidase assists in milk storage as well as it inhibits the propagation of psychrotropic bacteria. According to ${ }^{21}$ it positively affects the Gram negative catalysed coliform bacteria, pseudomonads, shigella and salmonella. Seifu et al. ${ }^{22}$ has reported that lactoperoxidase assembly is utilized as a natural preservation agent in dairy manufacturing in different regions especially tropical areas. The xanthine oxidoreductase has bactericidal effects and reduces the rate of $\mathrm{No}_{2}$ and results in cytotoxic nitric oxide production. It results in the production of hydrogen peroxide that acts as substrate for NADPH oxidase, and lactoperoxidase (component of proficient anti microbial systems)

\section{Functional dairy products}

Dairy products are prominent as natural healthy products that contain the most crucial elements of the balanced diet. In additions to nutritional benefits milk plays a significant role in the control of chronic diseases, example blood pressure was being 'treated' with dairy products. It may not seem obvious to discuss blood pressure in relation to weight management, but the link between dairy components and weight management was initially derived from blood pressure studies.

In Europe, dairy products are the major contributors in the functional food market by contributing approximately $60 \%$ of the total functional food spellings. ${ }^{23}$ They are the second well-liked class of functional foodstuff in the US and the consumers spend almost $\$ 5.0$ billion on dairy functional products in 2004. ${ }^{24}$ The Australian functional foods market is in its early life and is presently expected at $\$ 57.0$ million where probiotic yogurt is being the head in this zone that is growing at $22 \%$ and the soy yogurt resides at second. FAO/ WHO standards describe the yogurt as 'lactic acid fermentation by the activity of Lactobacillus delbrueckii and Streptococcus thermophilus (St. thermophilus) to produce a coagulated milk. ${ }^{25}$ Food Standards Australia and New Zealand (2006) defined low fat yogurt as 'the yogurt synthesized by culturing low fat or skim cow's milk that results in a thickened yogurt and does not have flavoring or fruit. It has $0.3 \%$ fat and $6.6 \%$ protein on average. Diary probiotic products can be produced by incorporation of probiotic bacteria in both of fermented and unfermented mix as reported by Homayouni et al. ${ }^{12}$ The work done on the diary probiotic products is summarized in Table1.

Shah $^{31}$ quoted that fermented milk is a prepared through mixed starter fermentation by using a culture comprising of St. thermophilus and $L$. delbrueckii. In Australia, lactic acid bacteria are allowed to employ as a starter cultures. Consequently, some yoghurt manufacturer use L. jugurti and L. helveticus for producing of yoghurt. Conversely, the standards in US do not allow any starter culture to be used other than St. thermophilus and Lactobacillus delbrueckii. The supplementation of different fruit provision in fermented milk products further endorse the healthy image of fermented milk that 
incorporate the fruits benefits. They provide antioxidants and fibre as described by O Rell. ${ }^{32}$ Recently, corn milk ${ }^{33}$ soy milk ${ }^{34-36}$ and peanut milk $\mathrm{k}^{37}$ depending on fermented milk products are being synthesized as an alternate of vegetarian bovine milk fermented products that also overcome the allergencity of milk protein. Furthermore, to enhance functionality of fermented milk that by addition of plant extracts such as antioxidative and tea catechin is also significantly considered. ${ }^{38}$
Various essential nutrients and different components are provided by fermented milk that regulates various body functions in an optimistic way. It is confirmed by various scientific evidences that chronic disorders i.e. coronary heart disease, osteoporosis, hypertension and cancer can be controlled by the ordinary utilization of probiotic or prebiotic supplemented fermented milk. Therefore the fermented milks meet with the functional food standards.

Table I A summary table for diary probiotic products

\begin{tabular}{|c|c|c|c|}
\hline $\begin{array}{l}\text { Dairy probiotic } \\
\text { foods }\end{array}$ & Probiotic strains & Characteristics & References \\
\hline Probiotic ice cream & $\begin{array}{l}\text { Lactobacillus casei }(\mathrm{Lc} 01) \text { and } \\
\text { Bifidobacterium lactis (Bb12) }\end{array}$ & $\begin{array}{l}\text { Highest resistance to simulated acidic, alkaline and ice cream } \\
\text { conditions }\end{array}$ & 26,27 \\
\hline Petit-suisse cheese & Bifidobacteria and lactobacilli & $\begin{array}{l}\text { The presence of the prebiotics insulin and oligofructose can } \\
\text { promote growth rates besides increased lactate and short } \\
\text { chain fatty acids production }\end{array}$ & $28 \mathrm{sa}$ \\
\hline $\begin{array}{l}\text { Conventional } \\
\text { yoghurt }\end{array}$ & L. acidophilus and B. bifidum & Add extra nutritional and physiological values & 12 \\
\hline Bio-yoghurt & L. acidophilus and B. bifidum & $\begin{array}{l}\text { Have to retain viability and activity in yoghurt as a probiotic } \\
\text { at consumption time. }\end{array}$ & 29 \\
\hline Probiotic milk & Lactobacillus acidophilus & $\begin{array}{l}\text { Remained viable in sweet acidophilus milk over } 28 \text { days at } \\
7^{\circ} \mathrm{C}\end{array}$ & 30 \\
\hline
\end{tabular}

\section{Conclusion}

This paper reviewed and discussed some of the findings regarding the role of milk health and dairy products as functional foods. In general, dairy products provide a solid nutritional base for losing weight. Diary's dietary minerals may play an important role by influences adipocyte metabolism through calcitrophic hormone, and decrease the energy available from fat in food products by forming undigestable complexes. The functional dairy components significantly contribute to the prevention of several diseases like hypertension, obesity, cancer, diabetes, and some transmissible diseases. On another hand, there is much kind of applications of these bioactive diary components such as phosphopeptides are currently used as both dietary and pharmaceutical supplements. Many of the components found in milk may have a protective effect against the onset of disease that occurs as a result of overweight, As well as several components found in milk could be sort and use in especial applications for individuals that do not consume dairy or may be lactose intolerant.

\section{Acknowledgements}

None.

\section{Conflict of interest}

The author declares no conflict of interest.

\section{References}

1. Davies JE, Freed V, Whittemore FW. An agro medical approach to pesticide management. Coral Gables, USA: University of Miami School of Medicine Washington DC; 1986.

2. Gasmalla M, Khadir K, Musa A, et al. Evaluation of some physicochemical parameters of three commercial milk products. Pakistan J Food Sci. 2013;23(2):62-65.
3. Kholif AM, Abo El-Nor SAH, Abou-Arab AAK, et al. Effect of spraying diazinon to control the external parasites on the productive performance of dairy animals. I. Yield and composition of buffalo's and Friesian cow's milks. Egypt J Dairy Sci. 1994;22:145-154.

4. Zemel MB, Thompson W, Milstead A, et al. Calcium and dairy acceleration of weight and fat loss during energy restriction in obese adults. Obes Res. 2004;12(4):582-590.

5. Moore LL, Singer MR, Bradlee ML, et al. Intake of fruits, vegetables, and dairy products in early childhood and subsequent blood pressure change. Epidemiol. 2005;16(1):4-11.

6. Vollmer WM, Sacks FM, Svetkey LP. New insights into the effects on blood pressure of diets low in salt and high in fruits and vegetables and low-fat dairy. Curr Control Trials Cardiovasc Med. 2001;2(2):71-74.

7. Abbott RD, Curb JD, Rodriguez BL, et al. Effect of dietary calcium and milk consumption on risk of thromboembolic stroke in older middle-aged men. Stroke. 1996;27(5):813-818.

8. Kampman E, Slattery ML, Caan B, et al. Calcium, vitamin D, sunshine exposure, dairy products and colon cancer risk (United States). Cancer Causes Control. 2000;11(5):459-466.

9. Holt PR. Dairy foods and prevention of colon cancer: human studies. $J$ Am Coll Nutr. 1999;18(5s):379S-391S.

10. Mccabe LD, Martin BR, Mccabe GP, et al. Dairy intakes affect bone density in the elderly. Am J Clin Nutr. 2004;80:1066-1074.

11. Savaiano D. Lactose intolerance: a self-fulfilling prophecy leading to osteoporosis. Nutr Rev. 2003;61(6):221-223.

12. Homayouni A, Alizadeh M, Alikhah $\mathrm{H}$, et al. Functional dairy probiotic food development: trends, concepts, and products, Everlon Cid Rigobelo editors. Immunology and Microbiology "Probiotics". 2012.

13. Fox PF. Indigenous enzymes in milk. J Adv Dairy Chem. 2003;1:447-467.

14. Bhat Z, Bhat H. Milk and dairy Products as Functional Foods: A review. Int J Dairy Sci. 2011;6(1):1-12. 
15. Donovan SM. Role of human milk components in gastrointestinal development: current knowledge and future needs. J Pediatr. 2006;149:4961 .

16. Morrow AL, Ruiz Palacios GM, Jiang X, et al. Human-milk glycan inhibit pathogen binding protect breast-feeding infants against infectious diarrhea. J Nutr. 2005;135(5):1304-1307.

17. Newburg DS. Innate immunity and human milk. J Nutr. 2005;135:13081312 .

18. Pouliot Y, Gauthier SF. Milk growth factors as health products: some technological aspects. Int dairy j. 2006;16(11):1415-1420.

19. Harrison R. Structure and function of xanthin oxidoreductase: where we are now? Free rad Biol med. 2002;33(6):774-797.

20. Maga EA, Anderson GB, Culler JS, et al. Antimicrobial properties of human lysozyme transgenic mouse milk. J Food Protect. 1998;61(1):5256.

21. Reiter B, Perraudin JP. Lactoperoxidase: biological functions. In Everse J, et al. editors. Peroxidases in Chemistry and Biology. Vol. 1, Boca Raton: Florida, USA: CRC Press; 1991. p. 143-180

22. Seifu E, Buys EM, Donkin EF. Significance of the lactoperoxidase system in the dairy industry and its potential applications. Rev Trends Food Sci Technol. 2005;16(4):137-154.

23. Shortt CD Shawand, Mazza G. Overview of opportunities for healthenhancing functional dairy products. In Shortt C. et al. editors. Handbook of Functional Dairy Products. New York, USA: CRC Press; 2004. p. 1-12.

24. Vierhile T. Functional 'add-ins' boost yogurt consumption. J Food Tech. 2006;60:44-48.

25. Krasaekoopt W, Bhandari B, Deeth H. Comparison of gelation profile of yogurts during fermentation measured by RVA and ultrasonic spectroscopy. Int J Food Prop. 2005;8(2):193-198.

26. Homayouni A, Azizi A, Ehsani MR, et al. Effect of microencapsulation and resistant starch on the probiotic survival and sensory properties of synbiotic ice cream. Food Chem. 2008;111(1):50-55.
27. Homayouni A, Azizi A, Ehsani MR, et al. Growth and survival of some probiotic strains in simulated ice cream conditions. J App Sci. 2008;8(2):379-382.

28. Cardarelli HR, Saad SMI, Gibson GR, et al. Functional petit-suisse cheese: Measure of the prebiotic effect. Anaerobe. 2007;13(5-6):200-207.

29. Dave R, Shah NP. Viability of probiotic bacteria in yoghurt made from commercial starter cultures. Int Dairy J. 1997;7(1):31-41.

30. Vedamuthu ER. Other fermented and culture-containing milks. In: RC Chandan et al. editors. Manufacturing Yogurt and Fermented Milks. UK: Blackwell Publishing; 2006. p. 295-308.

31. Shah NP. Functional cultures and health benefits. Int $J$ Dairy. 2007;17(11):1262-1277.

32. Rell KR. Chandan RC. Fruit preparations and flavouring materials. In Ramesh C, et al. editors. Manufacturing Yogurt and Fermented Milks. UK: Blackwell Publishing; 2006. p. 151-166.

33. Supavititpatana P, Wirjantoro T, Apichartsrangkoon A, et al. Addition of gelatine enhanced gelation of corn-milk yogurt. Food Chem. 2008;106(1):211-216.

34. Champagne CP, Green Johnson J, Raymond Y, et al. Selection of probiotic bacteria for the fermentation of a soy beverage in combination with St. thermophilus. Food Res Int. 2009;42(5-6):612-621.

35. Ferragut V, Criz NS, Trujillo A, et al. Physical characteristics during storage of soy yogurt made from ultra high-pressure homogenized soy milk. J Food Eng. 2009;92(1):63-69.

36. Cruz NS, Capellas M, Jaramillo DP, et al. Soymilk treated by ultra highpressure homogenization: Acid coagulation properties and characteristics of a soy-yogurt product. Food Hydrocolloids. 2009;23(2):490-496.

37. Isanga J, Zhang G. Production and evaluation of some physicochemical parameters of peanut milk yogurt. LWT-Food Sci Tech. 2009;42(6):11321138.

38. Jaziri I, Slama MB, Mhadhbi H, et al. Effect of green and black teas (Camellia sinensis) on the characteristic microflora of yogurt during fermentation and refrigerated storage. Food Chem. 2009;112(3):614-620. 